\title{
To transport waste or transport recycling plant: Insights from life- cycle analysis
}

\author{
Guilhem Grimaud ${ }^{1,2}$, Bertrand Laratte ${ }^{2,3,}$, and Nicolas Perry ${ }^{2}$ \\ ${ }^{1}$ MTB Recycling, Trept, France \\ 2 Arts et Métiers ParisTech, I2M Bordeaux, Bordeaux, France \\ 3 APESA-Innovation, Tarnos, France
}

Received: 28 June 2017 / Accepted: 9 March 2018

\begin{abstract}
The purpose of this study is to determine the environmental and economic balance between a collection of waste requiring the transport to a centralized recycling plant versus the displacement of a recycling plant near the waste production's location. Two systems are compared in the study with economic and environmental Life cycle analysis (LCC and LCA) tools. The first one considers a centralized recycling plant that gathers batch of cables from different locations in Europe. The second scenario considers a transportable recycling plant, the Cablebox (designed by MTB Manufacturing), which is regularly carried to be close to the waste deposit to recycle waste cables. On the one hand, the study demonstrates huge environmental benefits for transportable recycling plants in comparison with the centralized system. The overall environmental impact is halved on the climate change indicator. On the other hand, the results show the economic advantages of such solution. The treatment cost per ton of recycling is reduced by 5 to $8 \%$. Transportable recycling solutions seem to be a good answer to solve End-of-Life logistic issues, both from an economic and an environmental point of view.
\end{abstract}

Keywords: recycling / LCA / LCC / industrial efficiency

\begin{abstract}
Résumé. Transporter les déchets ou transporter l'usine de recyclage : évaluation selon l'analyse de cycle de vie. Le but de cette étude est de déterminer les impacts environnementaux et économiques entre une collecte de déchets nécessitant le transport vers une usine de recyclage centralisée et le déplacement de l'usine de recyclage près du lieu de production de déchets. Deux systèmes sont comparés dans l'étude avec des outils d'analyse du cycle de vie économique et environnementale (LCC et ACV). Le premier système envisage une usine de recyclage centralisée qui rassemble des câbles provenant de différents endroits en Europe. Le deuxième système envisage une usine de recyclage transportable, la Cablebox (conçu par MTB Manufacturing), qui est régulièrement transportée à proximité des gisements de déchets pour les recycler. D'une part, l'étude démontre les avantages environnementaux de l'usine de recyclage transportable en comparaison avec le système centralisé. L'impact global sur l'environnement est réduit de moitié sur l'indicateur de changement climatique. D'un autre côté, les résultats montrent les avantages économiques d'une telle solution. Le coût du traitement par tonne de recyclage est réduit de 5 à $8 \%$. Les solutions de recyclage transportables semblent être une bonne réponse pour résoudre les problèmes de logistique en fin de vie, tant du point de vue économique qu'écologique.
\end{abstract}

Mots clés: recyclage / ACV / LCC / efficacité industrielle

\section{Introduction}

\subsection{Context of the study}

The rise of the world's population and its life conditions go hand in hand with the growth of energy and raw material consumption as well as the steadily growing $\mathrm{CO}_{2}$ concentration in the atmosphere $[1,2]$. Because of the lack of End-of-

\footnotetext{
* e-mail: bertrand.laratte@ensam.eu
}

Life (EoL) strategies, the consumption growth comes by an increase in the amount of waste produced annually $[3,4]$. The demand for primary resources is not sustainable in the long term [5]. It is therefore vital to find industrial solutions to maintain standards of living equivalent while also decoupling resource use and demand [6]. The circular economy offers a partial answer to solve the problem [7]. Recycling is inherent in circular economic strategies that is why industrial companies are developing recycling solutions in close loop [8]. The product centric EoL solutions using recycling show which permits unrestricted use, distribution, and reproduction in any medium, provided the original work is properly cited. 


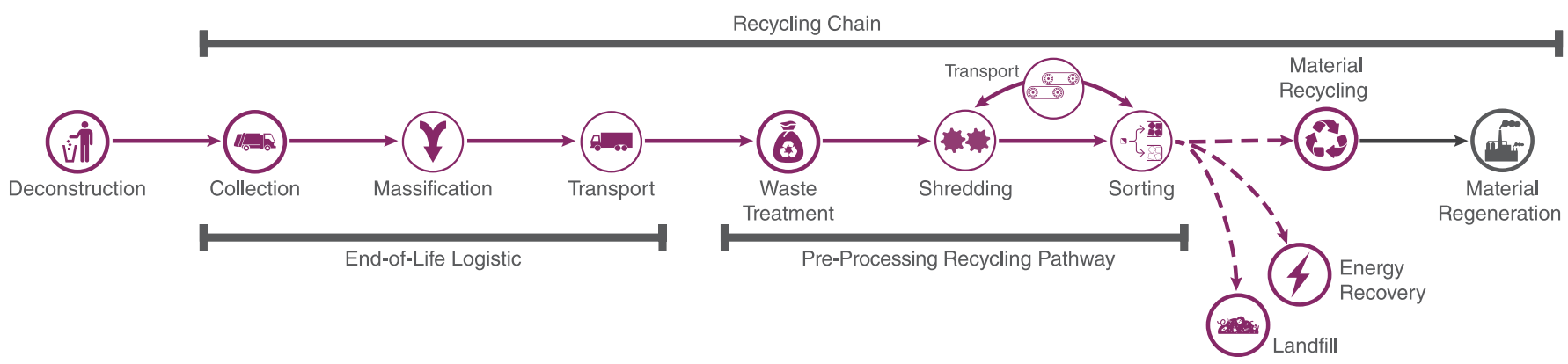

Fig. 1. Main steps of the cable end-of-life scenario.

Fig 1. Principales étapes du scénario de fin de vie des câbles.

good environmental performance. As a specific EoL strategy requires an efficient logistic system to reach the recycling plant; the paradigm shift is primarily motivated by economic considerations [9-11].

Large technical systems supporting the everyday needs of society such as telecommunication, power and water supply systems have generally been constructed and maintained in order to remain in service for long periods of time [12-15]. These systems largely use metals such as aluminium, copper, lead, steel, zinc, etc. The cable industry mainly uses copper for its very good conductivity properties and aluminium for its compromise between density and good conductivity properties [16]. To obtain optimal electrical conductivity, metals use for cables have a purity above $99.7 \%$ for aluminium and above $99.8 \%$ for copper [17].

From an economic point of view, the value of metals is even more important as their purity is high. In most cases, during the deconstruction stages a separate collection is done to maintain the value of these metals. The different steps of the EoL scenario are shown in Figure 1. In fact, a selective collection is easy to set up to consider a product centric EoL solution. As metal properties are not deteriorated by recycling, aluminium and copper from cables have a high recycling rate [18].

However, at the waste treatment stage, the EoL cables are often mixed with other types of waste without considering their provenance and use. When metallic waste are mixed together, the cost-effective solution for refining is furnaces. As the metal is molten, the separation is done using the buoyancy (decantation methods, centrifugation, filtration, flotation, etc.) [19]. Despite the technology optimization, a fraction of metal is unrecyclable [20] and some alloying elements are lost in the process [21]. It leads to a drop of the metal quality which is akin to a down-cycling and so, after recycling, the metals cannot meet the primary resource purity [22].

\subsection{Cables mechanical recycling: case of aluminium}

The Figure 2 is an illustration of an aluminium cable, the aluminium core (a) is covered with a polymer thick layer (b). Additional metallic materials (c) are coaxially integrated to reach the definition of this complex product. These cables are manufactured by extruding together all the materials that compose it. The glued assembly of many materials makes the product particularly homogeneous and hard to disassembly.

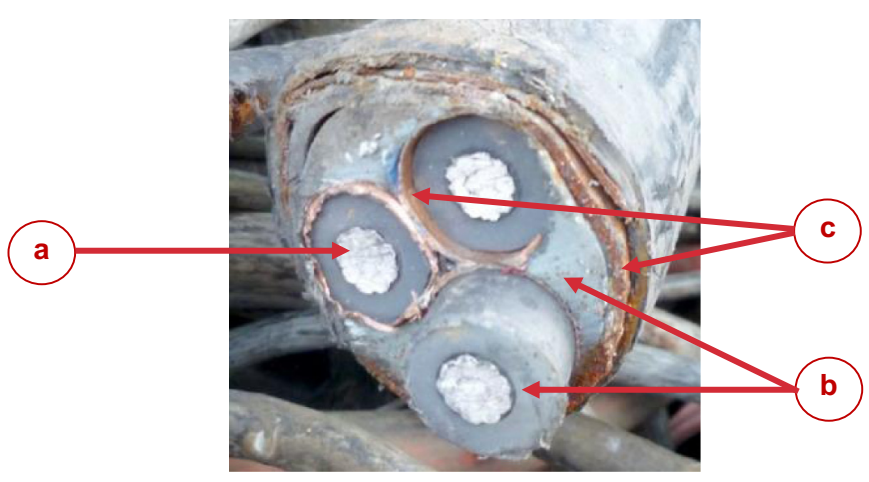

Fig. 2. Section of a cable with multiple aluminium beams.

Fig 2. Vue en coupe d'un câble électrique avec plusieurs faisceaux en aluminium.

Table 1. Composition of recycled aluminium cables at the MTB plant.

Tableau 1. Bilan matière du recyclage des câbles en aluminium à l'usine de MTB Recycling.

\begin{tabular}{lll}
\hline $\begin{array}{l}\text { Key on } \\
\text { Figure 2 }\end{array}$ & Material & $\begin{array}{l}\text { Proportion } \\
(\%)\end{array}$ \\
\hline (a) & Rigid aluminium & 48.5 \\
(b) & Plastics and rubber & 40.5 \\
& (PE, xPE, PVC, etc.) & \\
(c) & Non-ferrous metals & 4.5 \\
(c) & Ferrous metals & 4.0 \\
& (steel and stainless steel) & \\
& Flexible aluminium & 2.5 \\
\hline
\end{tabular}

The Table 1 shows the mass proportion of materials contained in aluminium cables. The first column refers to the keys present in Figure 2. Mass proportions are extracted from MTB monitoring data of recycled cables at the plant between 2011 and 2014. Aluminium in cables represents between 35 and $55 \%$ of the total weight. Other metals are mainly steel, lead, copper, zinc. The variety of plastics contained in the sheath is even stronger than for metals: silicone rubber, polyethylene (PE), cross-linking $\mathrm{PE}$ (xPE), polychloroprene (PCP), vulcanized rubber, ethylene vinyl acetate (EVA), ethylene propylene rubber (EPR), flexible PVC, etc. [23]. 


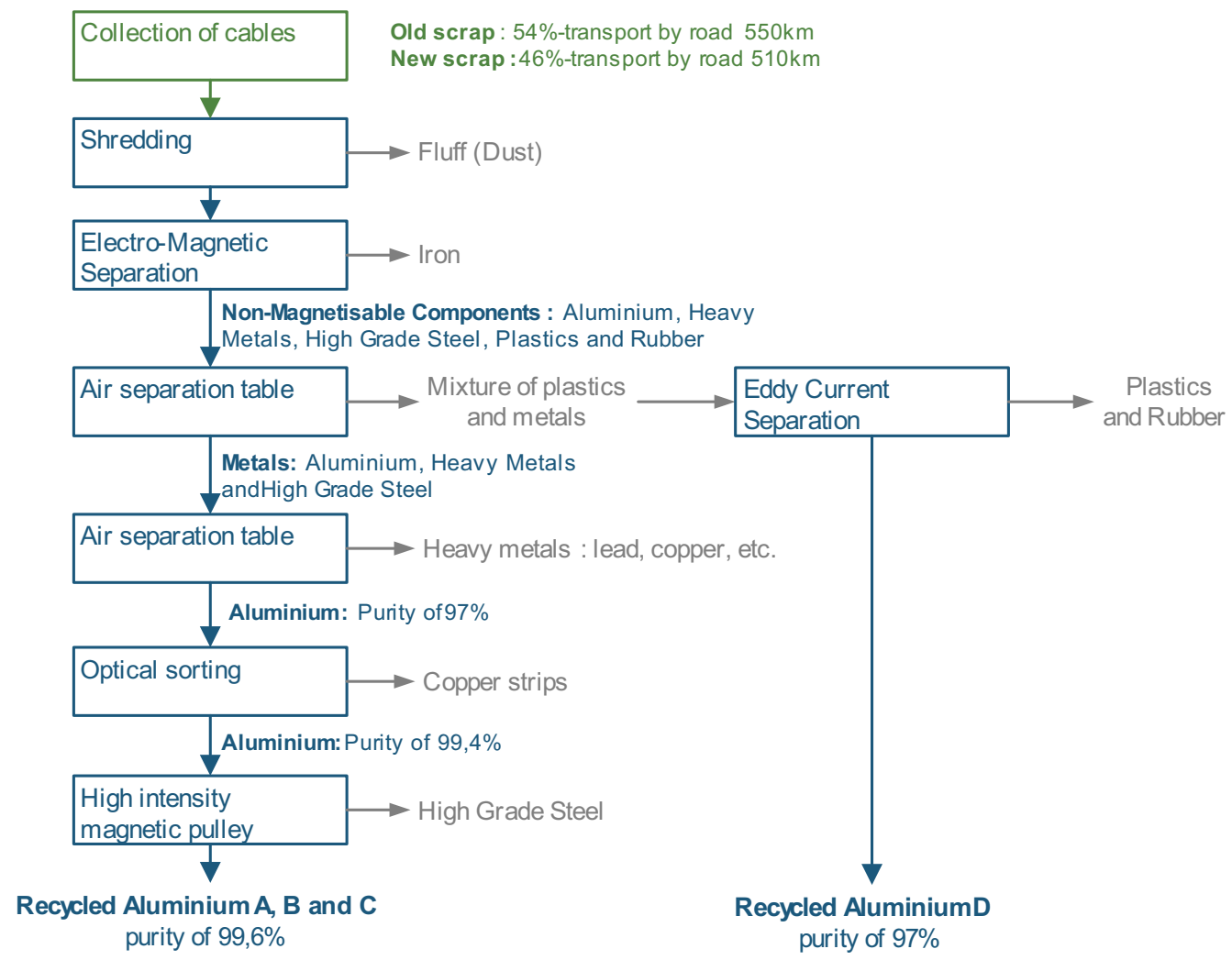

Fig. 3. MTB end-of life recycling process for aluminium cables.

Fig 3. Procédé MTB de recyclage des câbles en aluminium.

Aluminium cables represent about $8 \%$ of aluminium products in Western Europe [24]. The inherent purity of aluminium used for cables justifies differentiate recycling channels to optimize processing steps and to improve cost efficiency. At the EoL, the challenge concerns the separation of materials from each other. The most economical way to separate different materials relies on a smelting purification [25].

Even if the cables are complex objects composed by a multitude of materials, it is possible to carry out a mechanical recycling without smelting. Instead of thermal and wet separation, the alternative process to recycle the cables rely only on shredding and mechanical sorting. This mechanical recycling solution has notably been developed for several years by MTB, a recycling company located near Lyon in France. The specific recycling pathway developed by MTB is sold worldwide as a cable recycling system. This recycling solution reaches standard aluminium purity up to $99.6 \%$. It is thus possible to carry out mechanical recycling without neglecting the quality. This performance is obtained using only mechanical separation and optical sorting processes on shredder cables, as present in Figure 3. A similar system is in use for copper cables. Because a high purity makes it easy to produce a wide variability of alloys; aluminium and copper from cables mechanical recycling are specially appreciated by the smelter. Recycled aluminium and copper can then be used in many metallic products and not only in applications requiring alloys.

\subsection{Environmental impact of cable mechanical recycling}

A Life cycle assessment (LCA) [26,27] was conducted to evaluate the environmental impact of aluminium cable recycling. With the LCA results, we were able to compare the mechanical process with the traditional smelting process. As already demonstrated in previous publication [28], the mechanical recycling process makes it possible to halve the impact of recycled aluminium. The summary of the recycling LCA comparison results is shown in Figure 4. The results for MTB mechanical recycling process are given with two sets of data. The only difference between these two models concerns the electricity mix used. In yellow, the characterization is done using the equivalent European electricity mix (ENTSO-E) and in blue using a specific green electricity mix.

During the first LCA study, we have also compared the recycling systems to the baseline mining system available in Ecoinvent. The Ecoinvent modelling uses data from the average technology available on the market for Western Europe [29]. The mining system is based on the EAA life cycle inventory [30,31]. As expected the primary aluminium production system emerges as far more significant than other systems on all indicators in the LCA results. Also, in the present LCA study, this production system is not relevant.

Except for the ionizing radiation impact indicator, the impact of the MTB recycling system (in yellow in Fig. 4) represents between $5 \%$ and $82 \%$ of the recycling by melting 


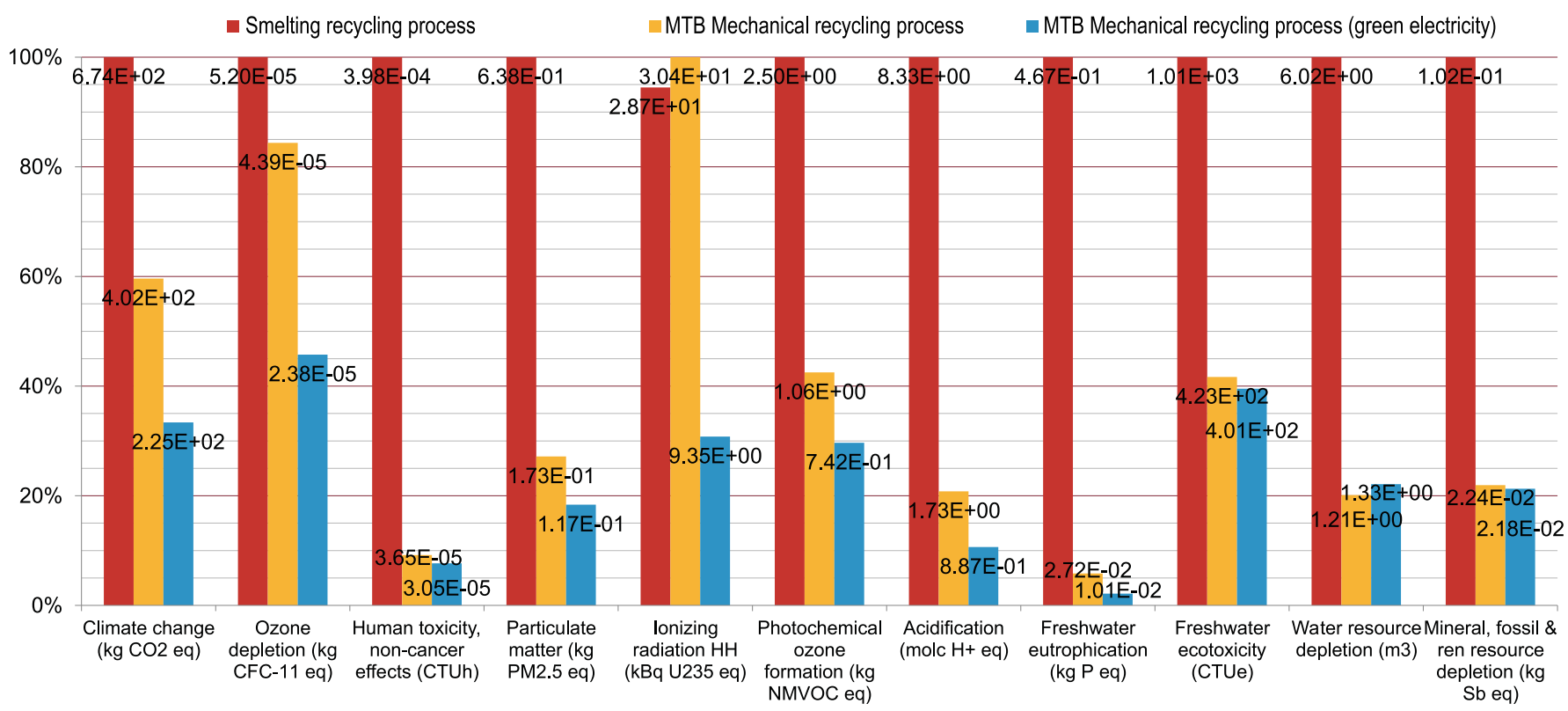

Fig. 4. Characterization of the two recycling pathways comparison using equivalent and specific electricity mix [34].

Fig 4. Caractérisation environnementale de deux systèmes de recyclage en utilisant un mix électrique équivalent et spécifique.

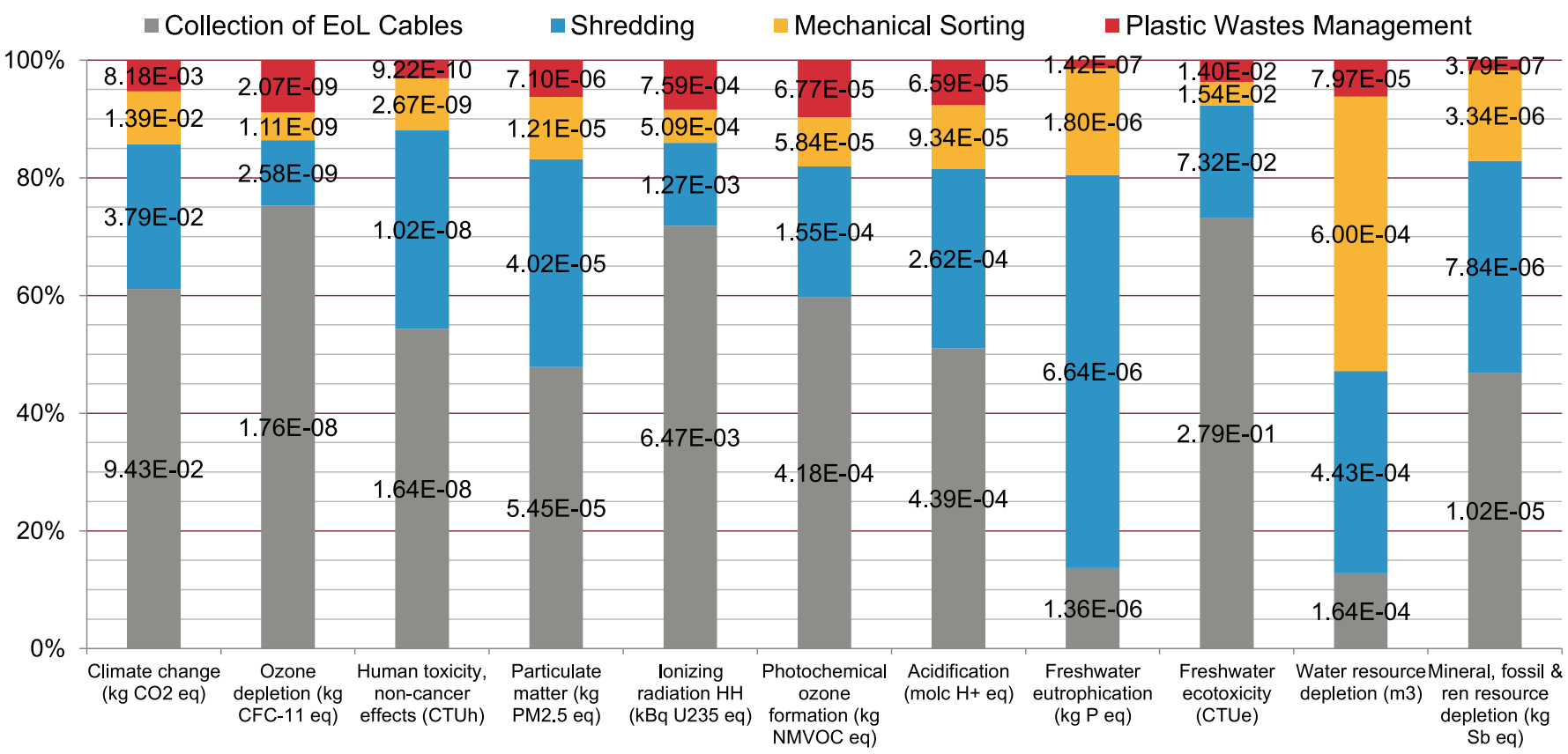

Fig. 5. Characterization of MTB recycled aluminium using specific electricity mix [34].

Fig 5. Contribution des processus du système de recyclage MTB des câbles en aluminium en utilisant le mix électrique spécifique.

scenario impact. The high electricity consumption during the shredding steps heavily contribute on this indicator. For the comparison of aluminium produced using specific green electricity mix (in blue on the Fig. 4), the impact does not exceed the impact of smelting recycling process. In addition, the impact of MTB recycling scenario represents between $2 \%$ and $46 \%$ of the recycling by smelting impacts.

Results from Figure 4 also show the environmental relevance of the product centric recycling approach for cables recycling. The LCA revealed that the closed loop option (considering aluminium cables) has lower environmental impact over the other recycling scenario using mixed aluminium scraps. This performance has already been demonstrated for aluminium cans [32] and for other materials [33].

Thanks to MTB recycling pathway, on the set of indicators, the environmental impact of recycled aluminium is divided by four. These results allow us to establish a hierarchy between environmental recycling solutions for aluminium cables. Whatever the electricity mix used by 


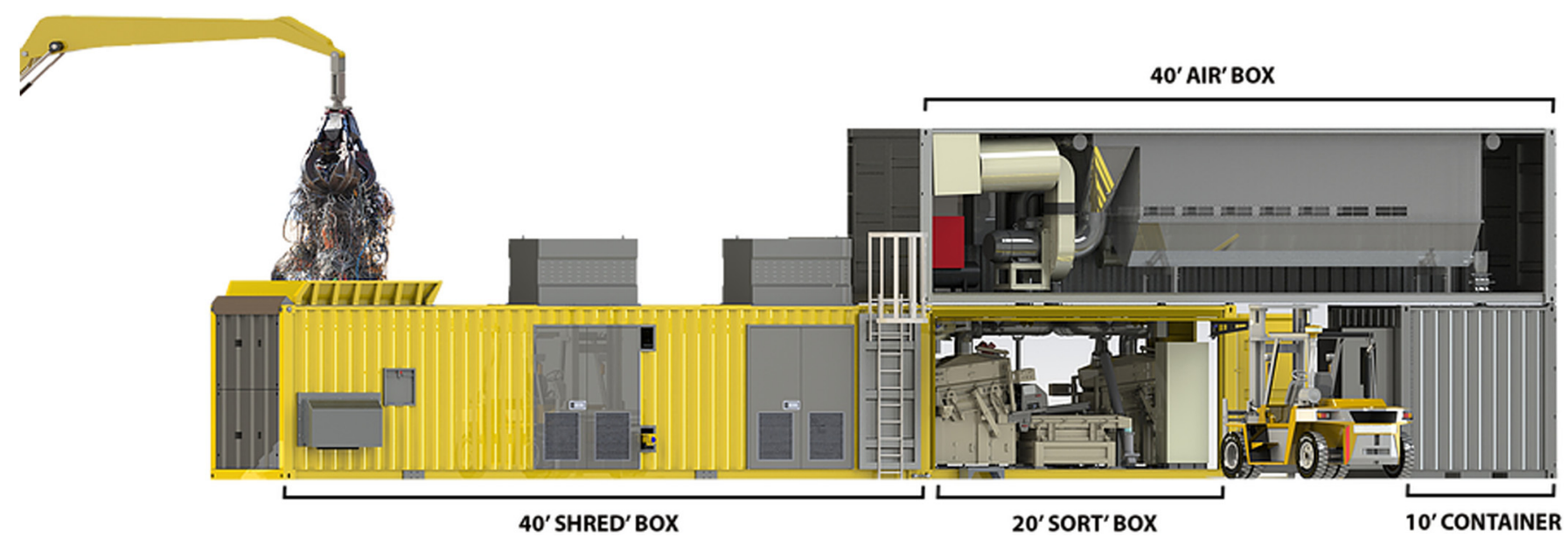

Fig. 6. 3D view of the Cablebox CBR2000 system.

Fig 6. Vue 3D du système de recyclage Cablebox CBR2000.

the recycling plant, the MTB mechanical recycling process is the most environmentally friendly pathway. It also demonstrates that recycling when driven without loss of quality is a relevant alternative to mining.

This attractive performance hides a hotspot: the Endof-life logistic. The transportation is the main contributor to the overall impact of the mechanical recycling system. The Figure 5 shows the results for the characterization of the MTB aluminium recycling pathway, with the specific renewable electricity mix used at the MTB recycling plant. The values used for the representation are given on the figure. The results show a very strong contribution from the EoL logistic for the collection of waste in the total impact of the scenario.

On the set of indicators, the MTB recycling steps represent between $11.4 \%$ and $79.7 \%$ of the total impact, the remaining impact share is related to transportation. On the 11 indicators, the average is equal to $36.1 \%$, and the median is $33.0 \%$. Indeed, before reaching the treatment plant, old and new scraps have travelled $530 \mathrm{~km}$ on average (Fig. 8).

\subsection{Moving recycling plant instead of moving waste to plant}

Using LCA gives good results to improve the environmental performances of industrial processes [35]. Beyond the LCA results, MTB has been able to identify ways to improve the recycling pathway. The extensive study of the main contributors and hotspots has allowed MTB to implement corrective actions to reduce the impact of its mechanical recycling process. The authors return in detail on this work in a second publication [36]. All these actions concern only the pre-processing steps within the factory, but not the EoL logistics.

To further reduce the environmental impact of cables recycling, MTB had to review the overall recycling chain (Fig. 1) and not just the industrial processes. First, we studied the possibility of optimizing the logistic routes, or even increasing the filling rates of the collection trucks. However, these solutions only provide a partial answer. MTB therefore launched the challenge of designing a
Table 2. Presentation of the various components of the Cablebox.

Tableau 2. Présentation des équipements de la Cablebox.

\begin{tabular}{llll}
\hline Name & Size (ft) & Weight $(\mathrm{t})$ & Function \\
\hline Shred' box & 40 & 30 & $\begin{array}{l}\text { Pre-shredding and } \\
\text { granulation unit }\end{array}$ \\
Sort' box & 20 & 10 & $\begin{array}{l}\text { Sorting unit } \\
\text { Air treatment and } \\
\text { R' box }\end{array}$ \\
& 40 & 11 & $\begin{array}{l}\text { remediation unit } \\
\text { Dust storage and } \\
\text { utility unit }\end{array}$ \\
Utility box & 10 & 3 & \\
\hline
\end{tabular}

transportable recycling solution capable of achieving the same level of purity as its existing centralized plant but with a lower flow rate. So, instead of bringing the waste to the recycling plant, it is the plant that moves closer to the deposits. The concept of the Cablebox was born!

The Figure 6 shows the Cablebox CBR 2000, the first transportable plant for cables recycling. It takes place in two 40-foot containers, one 20 -foot container and one 10 foot container. The details of the various components of the Cablebox are given in Table 2 . The flow rate reached with the CBR 2000 version is $2 \mathrm{t} / \mathrm{h}$. Compared to the MTB recycling plant at Trept, the flow rate is divided by two. A first unit of Cablebox production has been in operation since January 2017 in the United States of America. Since February 2018, ten new units are used worldwide.

The use of the international container standard sizes ensures maximum transportability by all modes of transport (road, rail and maritime). In addition, the containers offer modularity with upstream and downstream processes that can be easily connected. The Cablebox system is not autonomous, it requires an external power source. The electricity mix used for the local supply of the system depends on the location. There are no direct local emissions but only indirect emissions due to the electricity consumption. 


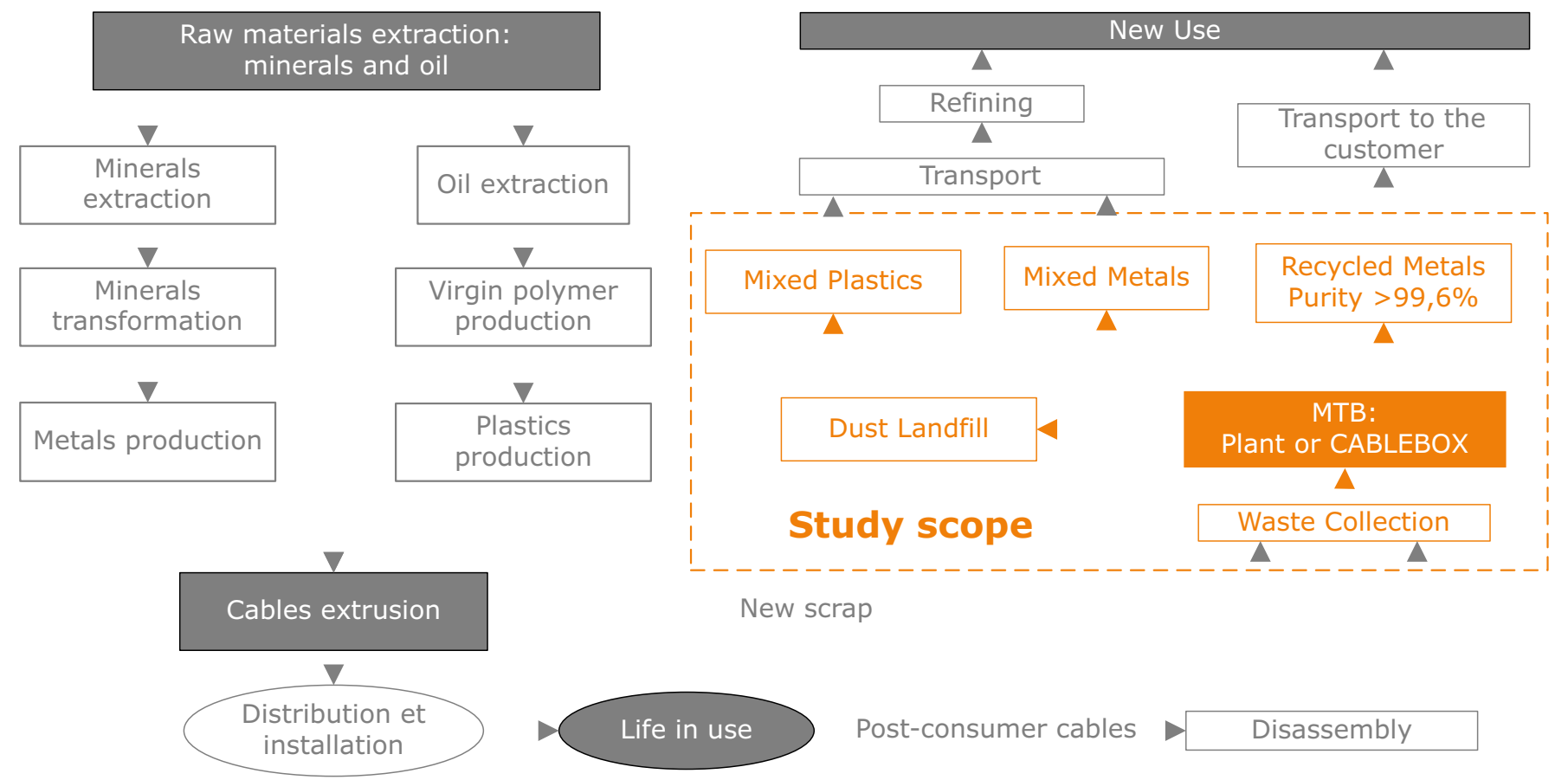

Fig. 7. Study scope for the cable recycling system boundaries.

Fig 7. Champ de l'étude pour le système de recyclage des câbles.

We therefore wanted to know if the Cablebox approach was more relevant from an environmental and economic point of view, using economic and environmental Life cycle analysis (LCC and LCA) tools. In the rest of this article, we present the study conducted to determine the environmental and economic balance between a collection of waste requiring the transport to a centralized recycling plant versus the displacement of a recycling plant near the waste production location.

\section{Materials and methods}

\subsection{Scope of the study}

The study is based on a life cycle approach, in accordance with ISO 14040/44 standards [28,29]. The Figure 7 presents the study scope used for the life cycle comparison. The boundaries include cradle to exit gate stages $[37,38]$. Life in use of materials in cables and new products are not included in our study scope. The study only focuses on recycling steps of metals. As shown in Figure 7, by-products are included in environmental impacts calculation, but no environmental and economic benefit of by-products recycling is integrated into the study.

In Figure 7, the orange block MTB: plant or Cablebox can be defined by the MTB centralized recycling plant system or the Cablebox transportable recycling system. The boundaries are the same for the two systems. Smelting plants for refining mixed metals are well dispatched on the territory, so we assume that downstream transport is similar to the two scenarios. At the MTB plant, we have the necessary equipment to separate plastics from each other. This additional treatment line is not considered in this study. However, MTB is planning to integrate all these technologies as an additional container to handle the mixed plastics outflow from Cablebox.

\subsection{Development scenario}

\subsubsection{MTB centralized recycling plant system}

For the MTB centralized recycling plant system, we use data from the MTB recycling treatment line located in Trept, France. The Table 3 presents the technical data. This treatment line has been reviewed by a complete LCA [34] and briefly discussed in the introduction section. In this article, we propose only a simplified presentation of the life cycle inventory to compare with the Cablebox system which was not been assessed with the previous LCA.

The working time is fixed on a 250 -working-day basis including ten days of complete shutdown for maintenance. The daily maintenance is carried out by night at regular intervals. The line automation makes it possible to limit the workforce to 2.5 operators. One half-time crane operator at the beginning of the recycling process and two operators for the handling at the end of the recycling process. Waste collection takes place at an average distance of 535 kilometres (Fig. 8) by articulated lorry. The lorry average load is 23 tonnes. A total of nearly 700 trucks are required each year to supply the recycling plant. Supply is not exclusively done in France and can also take place in neighbouring countries.

\subsubsection{Cablebox transportable recycling system}

The technologies introduced in the Cablebox system are similar to those used by the treatment line of the MTB centralized recycling plant system. The machines are 


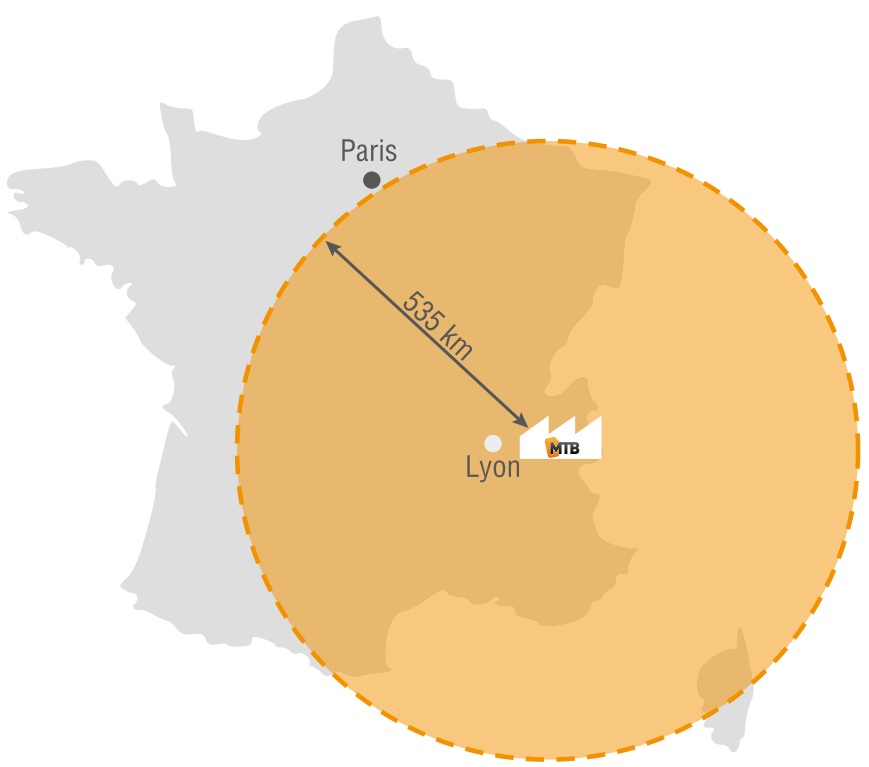

Fig. 8. Theoretical waste collection zone in France for the MTB recycling plant in Trept.

Fig 8. Zone de collecte des déchets pour l'usine de recyclage de Trept.

Table 3. Main specifications of the MTB cables recycling plant at Trept (FR).

Tableau 3. Principales spécifications de l'usine de recyclage des câbles MTB située à Trept (FR).

\begin{tabular}{lll}
\hline Specifications & Value & Comments \\
\hline Output & $4 \mathrm{t} / \mathrm{h}$ & Measured median value \\
Annual tonnage & $15,360 \mathrm{t}$ & Measured value \\
Electric power installed $1.479 \mathrm{~kW}$ & Technical data \\
Electric charge rate & $58 \%$ & Measured value \\
Annual working time & $3.840 \mathrm{~h}$ & Calculated value \\
\hline
\end{tabular}

smaller and have been optimized from an energy and caloric point of view to operate in a container-type enclosure. The electricity consumption reduction is the result of an extensive work on the shredding systems.

These developments have made it possible to reduce the installed power capacity for a treatment flow that remains high compared to the system size. However, downsizing has consequences on the types of waste that can be recycled. Cables with diameters greater than 415 millimetres cannot be treated with Cablebox. Also, the centralized system can work in a hidden time on pre-shredding steps using a storage solution, while the transportable solution requires continuous feeding solution. This consequence has a direct impact on the energy consumption, because some equipment could be stopped on the centralized system whereas this is impossible with the Cablebox.

The main specifications of the Cablebox CBR 2000 unit are summarized in Table 4. Over a year, we consider a 250working-day basis including 20 transit days and 230 days of
Table 4. Main specifications of the Cablebox CBR 2000.

Tableau 4. Principales spécifications de la Cablebox CBR 2000.

\begin{tabular}{lll}
\hline Specifications & Value & Comments \\
\hline Output & $2 \mathrm{t} / \mathrm{h}$ & Measured median value \\
Annual tonnage & $6.000 \mathrm{t}$ & Calculated tonnage \\
Electric power installed & $330 \mathrm{~kW}$ & Technical data \\
Electric charge rate & $65 \%$ & Measured value \\
Annual working time & $3.680 \mathrm{~h}$ & Estimated value \\
\hline
\end{tabular}

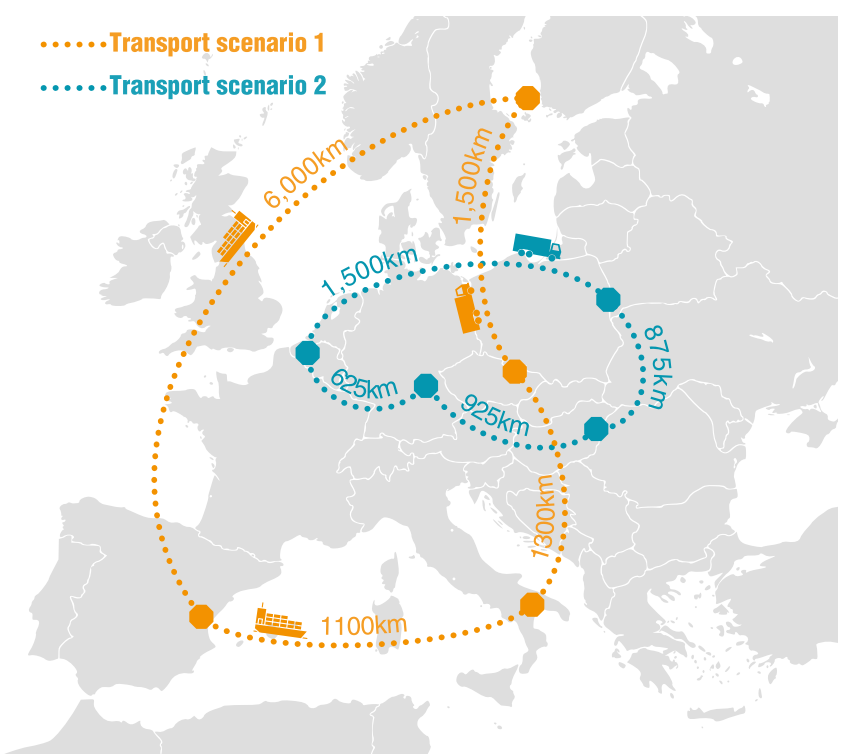

Fig. 9. Map of Cablebox system travel scenarios in Europe.

Fig 9. Cartographie des scénarios de transport de la Cablebox en Europe.

production. The operating scenario of the Cablebox system is organized in two teams working 8 hours per day. The total worked hours per year is 3680 .

Unlike the centralized system in Trept, the Cablebox system moves to get closer to the waste production sites. The four containers of the Cablebox are transported on three lorries. The time required for the handling and the installation of the Cablebox system is one and a half day. The installation requires a crane for the duration of four hours. In our study, we have imagined two scenarios composed of four displacements per year. The Figure 9 presents the displacement scenarios for the Cablebox system:

- scenario 1 (in orange) is composed of four displacements made partly by lorry $(2800 \mathrm{~km})$ and by cargo ship $(7100 \mathrm{~km})$. On average, transit by lorry is carried out in two days, cargo trips result in a greater number of transit days (three to six days);

- scenario 2 (in blue) represents $3925 \mathrm{~km}$ travelled exclusively by lorry. 
Table 5. Data selection for transport life cycle inventory.

Tableau 5. Données d'inventaire sélectionnées pour le transport.

\begin{tabular}{ll}
\hline Lorry type & Ecoinvent data \\
\hline Ampliroll & Transport, freight, lorry 7.5-16 metric ton, \\
lorry & EURO5 \\
Articulated & Transport, freight, lorry 16-32 metric ton, \\
lorry & EURO5 \\
\hline
\end{tabular}

\subsubsection{Shared data for the two systems}

For the environmental life cycle impact assessment, the inventory data come from the Ecoinvent 3.3 database. The modelling of road transport was carried out using two types of truck presented in Table 5 .

For the comparison of the systems, we use several electric mixes. The first electricity mix used corresponds to the European electricity mix without Switzerland: market group for electricity, medium voltage / electricity, medium voltage / APOS, U-Europe without Switzerland. This is the standard energy mix used for the isoperimetric comparison. This electricity mix is equivalent to ENTSOE electricity mix already used in the aluminium LCA (Fig. 4). Nevertheless, the centralized plant MTB located in Trept has chosen to be supplied exclusively with renewable energy. The corresponding electrical mix in the Ecoinvent database is: market for electricity, medium voltage, label-certified / electricity, medium voltage, labelcertified / APOS, $\mathrm{U}-\mathrm{CH}$. The electricity mix uses mostly hydroelectric sources from altitude dams. Further in the document, the LCIA results using this specific electricity mix are marked green electricity. Modelling the tire shovel and the crane truck involve the following Ecoinvent data: machine operation, diesel, $\geq 74.57 \mathrm{~kW}$, low load factor.

For the two systems studied, we used the economic data shown in Table 6 below. It is important to consider this data as average values representative of the trend but not accurate for business secrets.

\section{Results}

\subsection{Life cycle cost and impact assessment methodology}

The life cycle modelling was done using OpenLCA V 1.5 software and Ecoinvent V3.3 database. The economic calculations were obtained from OpenLCA. Environmental impact assessment is done using ILCD Handbook recommendations [39]. In OpenLCA ILCD, 1.0.8 2016 Midpoint without long term was selected for the calculation. For environmental calculations, we only present results for the climate change indicator for this simplified environmental study. The impact factors selected from climate change is the 100-year IPCC baseline model [40]. The environmental impact allocation is based on a mass allocation.
In our study, the LCC analysis only considering the costs of each system regardless the profit from the sales of the recycled materials sales. The method used does not include the environmental costs of impacts [41].

\subsection{Life cycle cost assessment results}

The Life cycle cost (LCC) calculation gives us the results present in Table 7 below. In the column CBR tonnage, the values for centralized system of the waste collection, electricity consumption and working costs are given per the Cablebox annual tonnage (6000 tons). This adaptation makes it possible to compare the results directly with the Cablebox system. The Cablebox system is presented with the two transport scenarios shown in Figure 9. Maintenance costs per ton are considered similar for both systems. We do not report operating costs for reasons of trade secrecy.

\subsection{Environmental life cycle assessment results}

In the results section, we present the results of the environmental assessment per ton of recycled cables. Thus, the comparison basis is similar for both systems to allow comparison.

\subsubsection{Recycling system comparison}

With the European equivalent electricity mix, the Cablebox system is far less impacted than the centralized system. The results for climate change are shown in Figure 10. The environmental impact of the recycling system on climate change indicator is reduced by $60 \%$. This hierarchy is true on all the impact indicators of the ILCD methodology. The choice of a transportable solution is relevant from an environmental point of view.

Nevertheless, the choice of a renewable electrical power mix makes it possible to compensate the upstream logistic impact. Thus, allows the centralized system to remain competitive from an environmental point of view.

We also note that the Cablebox transport scenarios have little influence on the climate change final impact, about $2 \%$ in the examples studied.

\subsubsection{Details impact assessment of the compared systems}

In this section, we are interested in the contribution of life cycle stages to the final impact. The Figure 11 shows the process contribution for the compared recycling systems. The calculation was done for all the systems present in Figure 10. According to this result, the two scenarios of transportation for the Cablebox are very close, so we present only the scenario 1 in Figure 11.

For the scenario 1 of the CBR system, the electricity power required for the recycling process contributes to two thirds of the final climate change impact. Upstream logistics transport is the second-largest contributor with around $17 \%$ of the final impact. The Cablebox transport scenario represents $2 \%$ of the final climate change impact but the Cablebox installation is equal to $6 \%$ which seems to be a bit important regarding the time of use. 
Table 6. Shared economic values for the life cycle cost.

Tableau 6. Données économiques communes pour l'analyse économique.

\begin{tabular}{lll}
\hline Data & Value & Comments \\
\hline Waste transport costs & $2.85 € / \mathrm{km} /$ lorry & Average market value \\
Electricity price & $0.085 € / \mathrm{kWh}$ & French electricity data \\
Power shovel (Diesel) & $94 \mathrm{~kW}$ & Data from manufacturer \\
Worker cost & $50 € / \mathrm{h}$ & Gross salary \\
Working days & 250 days $/$ year & Assumption \\
\hline
\end{tabular}

Table 7. Life cycle cost assessment results for the two systems.

Tableau 7. Résultats de l'analyse économique des 2 systèmes.

\begin{tabular}{|c|c|c|c|c|}
\hline \multirow[b]{2}{*}{ Systems } & \multicolumn{2}{|c|}{ Centralized system } & \multicolumn{2}{|c|}{ Cablebox system } \\
\hline & Annual tonnage & CBR tonnage & Scenario 1 & Scenario 2 \\
\hline Cablebox transit & $€ 0$ & $€ 0$ & $40 \mathrm{k} €$ & $21 \mathrm{k} €$ \\
\hline Waste collection & $1.018 \mathrm{k} €$ & $398 \mathrm{k} €$ & $92.5 \mathrm{k} €$ & \\
\hline Electricity consumption & $293.8 \mathrm{k} €$ & $114.8 \mathrm{k} €$ & $68.2 \mathrm{k} €$ & \\
\hline Working cost & $600 \mathrm{k} €$ & $225 \mathrm{k} €$ & $561.6 \mathrm{k} €$ & \\
\hline Cost per tonne & $124.5 € / \mathrm{t}$ & & $117.5 € / \mathrm{t}$ & $114.6 € / \mathrm{t}$ \\
\hline
\end{tabular}

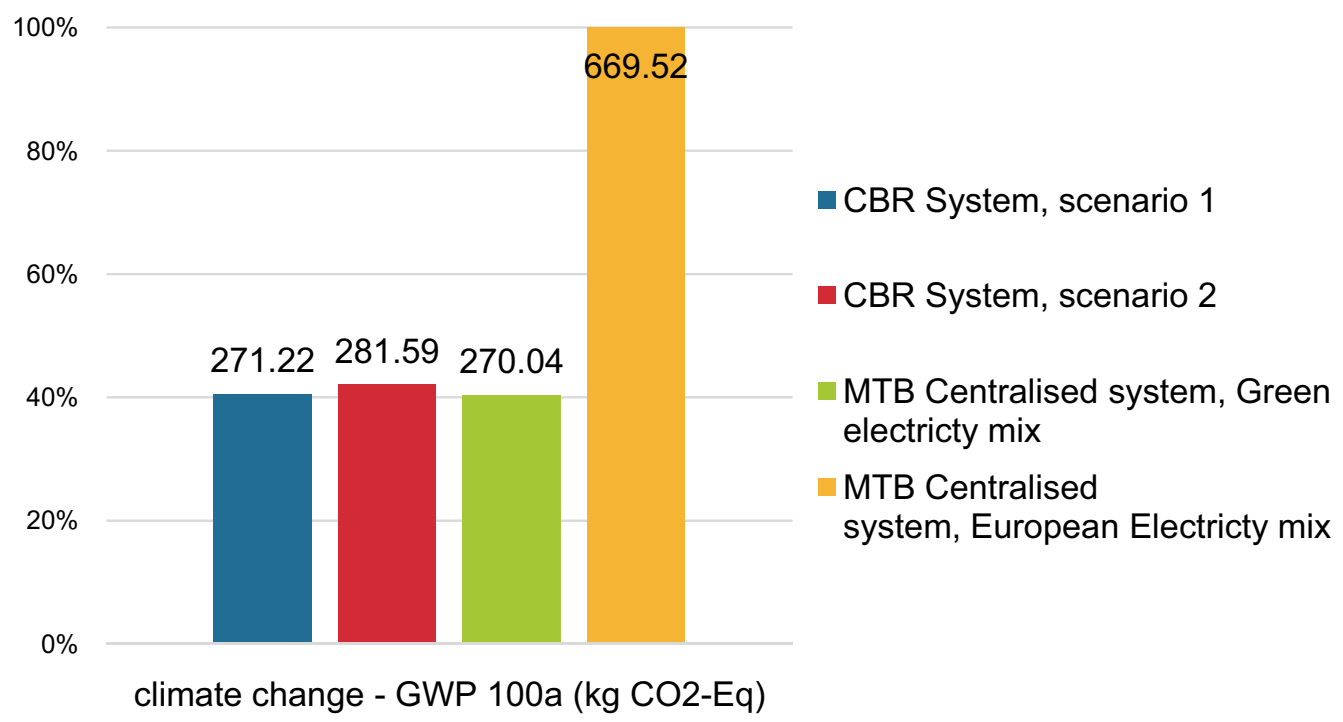

Fig. 10. Characterization of the two systems using equivalent and specific electricity mix.

Fig 10. Caractérisation environnementale des 2 systèmes avec mix électrique équivalent.

For the centralized system, the same calculation was done for the green electricity mix scenario and for the European electricity mix scenario. With the European electricity power mix, the impact of the recycling process is almost twice more impacting than the Cablebox system. However, the main difference is the contribution of transport, which is five times greater in centralized system for green electricity scenario as well as for the European electricity mix scenario than the transportable system. The results for the renewable electricity mix have already been detailed in the introduction section of this article based on Figure 5.

\section{Discussion}

In this study, we wanted to quantify the importance of transport impacts in recycling industry. Indeed, thanks to the optimization of recycling processes, the contribution of transport to the overall impact of recycled material 


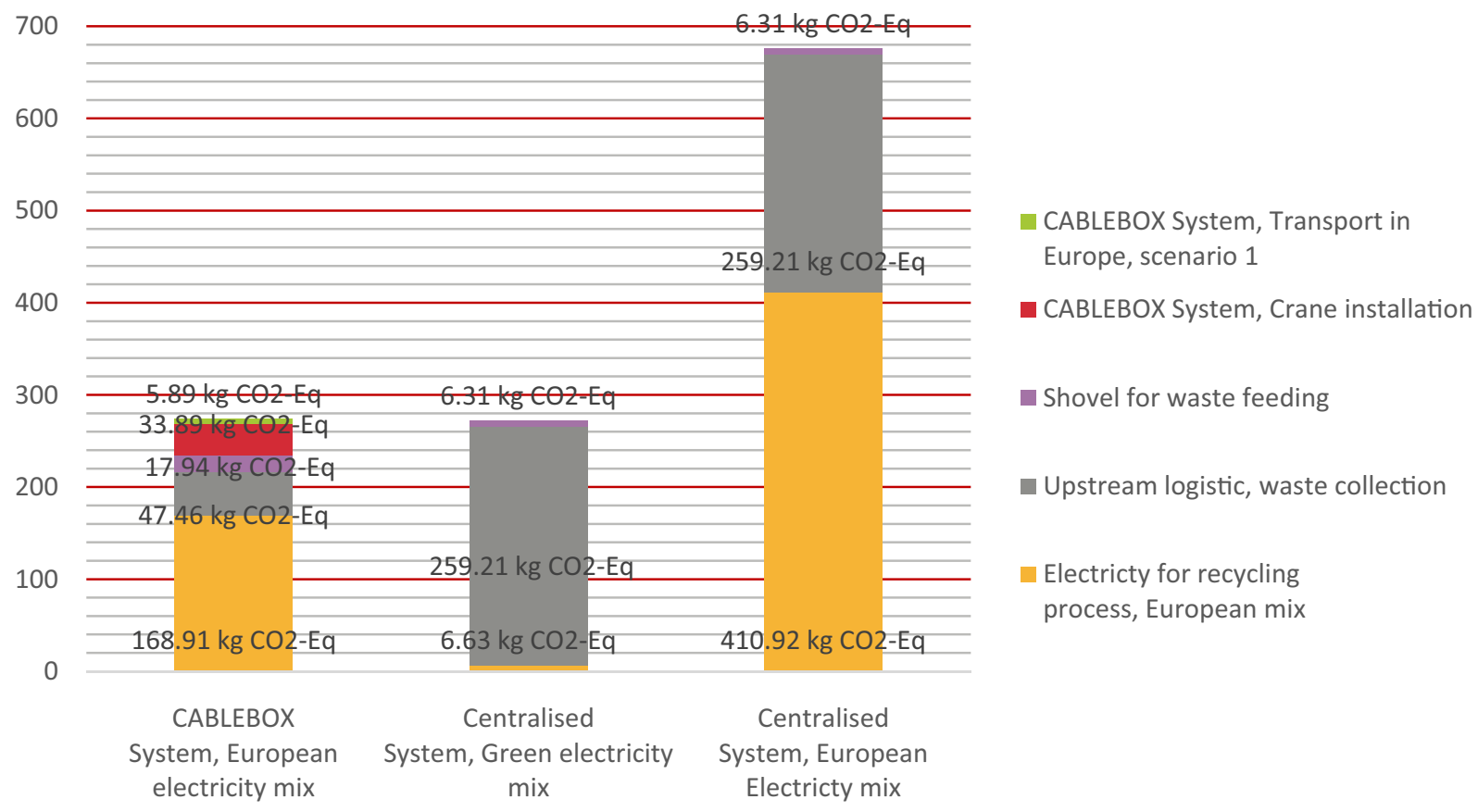

Fig. 11. Process contributions for the compared systems - climate change impact indicator.

Fig 11. Contributions des processus des systèmes comparés - indicateur de changement climatique.

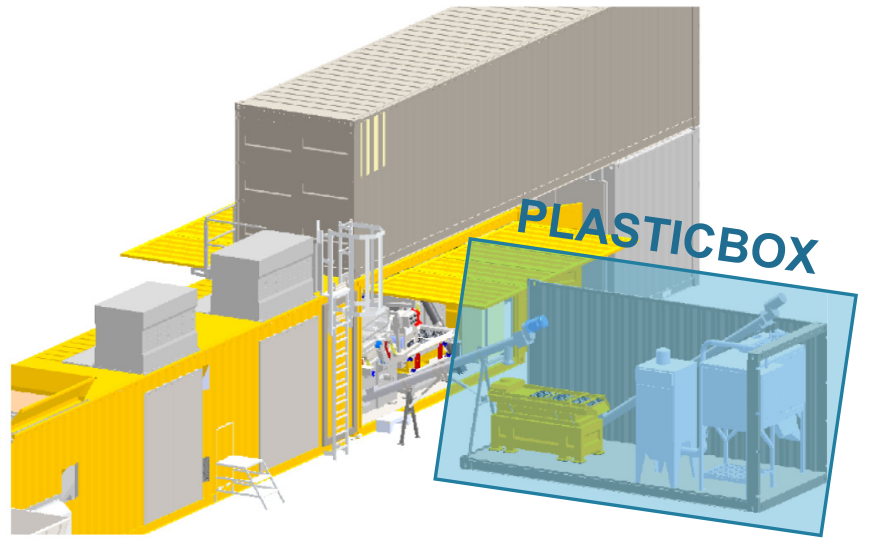

Fig. 12. 3D view of the Cablebox system with plastic recycling Plasticbox system.

Fig 12. Vue 3D du système Cablebox complété du système Plasticbox de recyclage des plastiques.

becomes quickly prevailing. It is therefore necessary to review the logistics flows to limit them to a minimum. However, logistic streams before and after treatment steps during the EoL scenario should be seen as a whole and not individually.

The overall view could bring both the recycling plant closer to waste production sites and close to recycled material consumers. This optimization logic should bring all product life stakeholders closer from each other, to take a step forward circular strategy. Indeed, compact and transportable recycling systems are perfect for

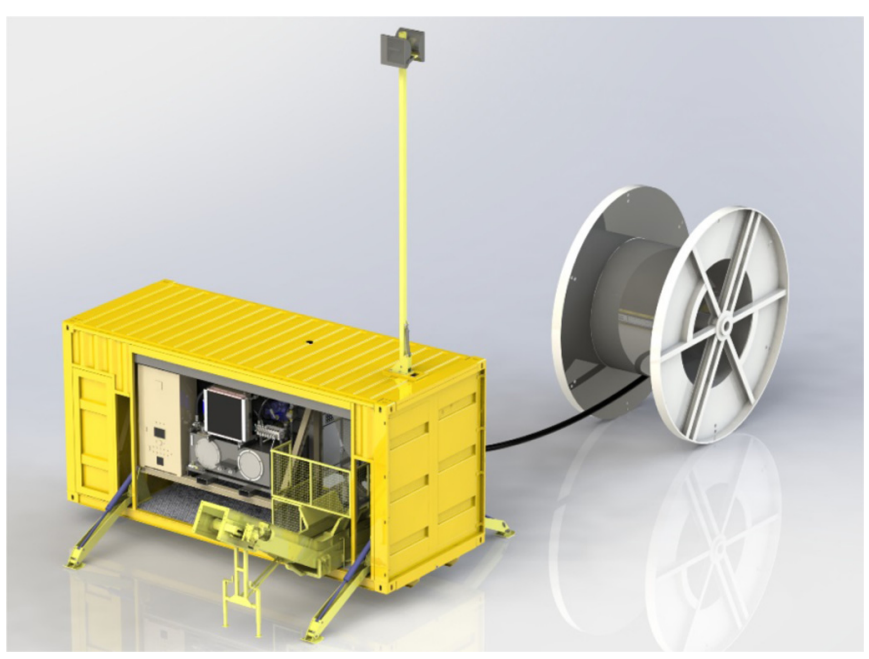

Fig. 13. 3D view of the Rollbox system designed by MTB for cable industry to cut cable out from cable drum.

Fig 13. Vue $3 D$ de la Rollbox, système de détourage des câbles pour les câbliers.

integration into a manufacturing plant to consider close loop recycling. So far, the cable industry has never used recycled material. Because secondary aluminium does not meet the quality requirements and cable manufacturers only use primary metals. In this case, Cablebox system seems really promising to foresee close loop recycling. MTB Engineering is working to duplicate this system to value the urban mine [12]. 
For the study, the two systems compared are isoperimetric. However, the centralized system makes it possible to go much further in material recycling, especially for non-ferrous metals and plastics sorting. The MTB Engineering team is currently working on additional transportable systems to go further in the recycling steps. For example, plastics sorting can be done in an additional 20-foot container: the Plasticbox system, visible in Figure 12.

Transportable recycling solutions cannot meet all needs. Despite this, Box systems have the merit of being a complementary approach to centralize recycling systems. The engineering team did not abandon the centralized system, and many optimizations on energy efficiency solved in the Cablebox systems were recently implemented in the centralized system. We are not able to communicate on the results thus far, but these can further reduce energy consumption. We plan to conduct a new environmental analysis to validate the optimizations.

In addition, these transportable solutions require skilled workforce which represents the main cost item for recycling through the transportable system. The design of a transportable recycling system must be accompanied by increased research on the automation of sorting technologies to guarantee the quality of recycled materials. Thus, the intervention and the judgement of the operators will be limited to guarantee a maximum level of quality.

When recycling plant integration at the place of production, logistics flows can still be optimized. The aim is to improve the waste transport to the place of treatment. A first option involves the modification of the route taken by truck. A second option concerns the truck load factor. The first option is approached by carriers. As for the second option, MTB recycling is trying to solve the issue. Indeed, the truck load factor for the cable transport is not limited by the cable density but by the cable volume. Cable waste is very bountiful and leaving large empty space. In addition, some waste cables are still reeled on cable drums. For these cable waste, MTB engineers designed an autonomous and transportable cable routing solution (Fig. 13).

\section{Conclusion}

Cablebox is the first integrated and transportable cable recycling solution. It is designed to be a system plug and run. This solution minimizes waste transport before recycling. Conversely, the flow rate is greatly reduced, and the process does not go as far in valorization as a centralized system does. While environmental gains are indisputable regardless of the electricity mix, whereas the economic gains obtained remain low. We struggle with the difficulty of correlating environmental and economic benefits. Our approach reveals the difficulty of responding to the three pillars of sustainable development.

For cables, EoL moving the recycling plant allows environmental and economic gains. Without a complete case-by-case study, it is impossible to judge the advantage of one system over the other. However, we can say with certainty that closed loop recycling by integrating the recycling plant within the production plant itself will always be more competitive than a centralized recycling system away from consumers of recycled materials. Beyond the environmental advantage, integrating the recycling plant into the production site also makes it possible to avoid the price of raw materials. In that case, only the marginal cost of recycling is integrated in the new products material cost.

Transportable recycling systems are interesting only in the case of a homogeneous distribution of producers and consumers on the territory. At the moment, urban mine stocks are very diffuse, whereas the production sites are increasingly centralized. Nevertheless, the recycling market trends are increasingly moving towards solutions of lower capacity. This new approach makes it possible to provide a personalized response for each waste stream. We must therefore address this challenge to ensure an adequate response in the future.

From an environmental perspective, the recycling by sector remains the most relevant. As already demonstrated for cables, although product centric recycling solutions show good environmental performance results; they concern only specific products. We must work on the development of this approach in the coming years to ensure efficient and consistent resource use. On a case-by-case basis, solutions are possible, but the right technologies adapted to each product remain to be defined. Moreover, optimizing recycling pathway systems is long and demands powerful assessment tools such as Mass flow analysis (MFA), LCC and LCA [35,42,43]. The first limit of this approach, results are obtained after entry into service of processes, the investment is already made. De facto, manufacturers are reluctant to improve efficiency [44,45].

Therefore, it seems to be necessary to develop an effective methodology to evaluate and guide process design choices to ensure economic, environmental and social efficiency [22]. Offer to designer an assessment tool will optimize the sustainable performance of pathways. Our team is focusing our research on this issue to offer recycling engineer tools to assess recycling pathways according to technical, economic and environmental performances [46].

Acknowledgments. The authors want to thank MTB Recycling and the French National Association for Technical Research (ANRT) for the funding of the PhD study (CIFRE Convention $\mathrm{N}^{0} 2015 / 0226$ ) of the first author.

\section{References}

1. T.F. Stocker, D. Qin, G.-K. Plattner, M.M.B. Tignor, S.K. Allen, J. Boschung, A. Nauels, Y. Xia, V. Bex, P.M. Midgley, Climate change 2013: the physical science basis, Intergovernmental Panel on Climate Change Thomas, Cambridge, 2013.

2. C. Yao, K. Feng, K. Hubacek, Driving forces of $\mathrm{CO}_{2}$ emissions in the G20 countries: an index decomposition analysis from1971 to 2010, Ecol. Inform. 26, 93 (2015). doi:10.1016/j.ecoinf.2014.02.003.

3. EUROSTAT, Statistics on waste in Europe, Stat. Explain. (2015). http://ec.europa.eu/eurostat/statistics-explained/ index.php/Waste_statistics/fr (accessed April 3, 2016). 
4. American Association for the Advancement of Science Working with Waste: Infography of World of Waste, Science (80) 337, 664 (2012). doi:https://doi.org/10.1126/sci ence.337.6095.664

5. R. Miehe, R. Schneider, F. Baaij, T. Bauernhansl, Criticality of material resources in industrial enterprises - structural basics of an operational model, 23rd CIRP Conf. Life Cycle Eng. 48, 1 (2016). doi:10.1016/j.procir.2016.03.035.

6. H. Schandl, Decoupling global environmental pressure and economic growth: scenarios for energy use, materials use and carbon emissions, J. Clean. Prod. 1 (2015). doi:10.1016/j. jclepro.2015.06.100.

7. W. McDonough, M. Braungart, Cradle to cradle: remaking the way we make things, Edition al, Manifesto, Paris, 2012.

8. G. Rebitzer, P. Fullana, B.P. Weidema, O. Jolliet, Recycling, close-loop economy, secondary resources, in: 10th LCA case study Symp., 2003, pp. 106-108.

9. J. Butterworth, A. Morlet, H.P. Nguyen, J. Oppenheim, M. Stuchtey, Towards the circular economy: economic and business rationale for an accelerated transition, Ellen MacArthur Found. 1, 98 (2013). doi:10.1162/108819806775545321.

10. A. Gahleitner, Closing the loop: next steps critical for Europe's circular economy, Eur. Alum. Assoc. 2, 2 (2015).

11. G. Lavery, N. Pennell, Le nouveau modèle industriel : plus de bénéfices, plus d'emplois et moins d'impact sur l'environnement, Interface, 2014.

12. UNEP, Metal Stocks in society - Scientific synthesis, 2005.

13. D. Panasiyk, B. Laratte, S. Remy, Steel stock analysis in Europe from1945 to 2013, Procedia CIRP. 48, 348 (2016). doi:10.1016/j.procir.2016.04.084.

14. B. Wallsten, D. Magnusson, S. Andersson, J. Krook, The economic conditions for urban infrastructure mining: using GIS to prospect hibernating copper stocks, Resour. Conserv. Recycl. 103, 85 (2015). doi:10.1016/j.resconrec.2015.07.025.

15. S. Spatari, M. Bertram, R.B. Gordon, K. Henderson, T.E. Graedel, Twentieth century copper stocks and flows in North America: a dynamic analysis, Ecol. Econ. 54, 37 (2005). doi:10.1016/j.ecolecon.2004.11.018.

16. C.E. Bruzek, A. Allais, D. Dickson, N. Lallouet, K. Allweins, E. Marzahn, Eco-friendly innovation in electricity transmission and distribution networks, Elsevier, 2015. doi:10.1016/ B978-1-78242-010-1.00007-0.

17. F. Goodwin, S. Guruswamy, K.U. Kainer, C. Kammer, W. Knabl, A. Koethe, G. Leichtfried, G. Schlamp, R. Stickler, H. Warlimont, Metals, in: W. Martienssen, H. Warlimont (Eds.), Handb. Condens. Matter Mater. Data Springer Berlin Heidelberg, Berlin, 2005, pp. 161-430. doi:10.1007/3-540-30437-1_5

18. UNEP, Recycling rates of metals, International, Paris, $20 \overline{1} 1$.

19. G. Rombach, B. Friedrich, Future potential and limits of aluminium recycling, in: W. Kuckshinrichs, P.N. Martens (Eds.), Resour. Anal. Met. Raw Mater., Matter and Materials, Jülich, 2003, p. 13.

20. H. Ohno, K. Matsubae, K. Nakajima, Y. Kondo, S. Nakamura, T. Nagasaka, Toward the efficient recycling of alloying elements from end of life vehicle steel scrap, Resour. Conserv. Recycl. 100, 11 (2015). doi:10.1016/j.rescon rec.2015.04.001.

21. D. Paraskevas, K. Kellens, W. Dewulf, J.R. Duflou, Sustainable metal management and recycling loops: life cycle assessment for aluminium recycling strategies, 20th CIRP Int. Conf. Life Cycle Eng. 404 (2013). doi:10.1007/ 978-981-4451-48-2_66.
22. J.M. Allwood, Squaring the circular economy: the role of recycling within a hierarchy of material management strategies, in: Handb. Recycl., Elsevier Inc., Amsterdam, 2014, pp. 445-477. doi:10.1016/B978-0-12-396459-5.00030-1.

23. Union technique de l'électricité (UTE), UTE C30-202Insulated cables and flexible cords - System for cable designation, Paris, France, 1990.

24. European aluminium association (EAA), Aluminium for future generations: progressing through dialogue $\mathbf{5 2}$ (2003).

25. European aluminium association (EAA), Global aluminium recycling: a cornerstone of sustainable development, International Aluminium Institute, London, 2006.

26. International Standard Organization, ISO 14040 - Environmental management - Life Cycle Assessment — Principles and Framework, International, 2006. doi:10.1002/jtr.

27. International Standard Organization, ISO 14044, Environmental management - Life cycle assessment - Requirements and guidelines, Geneva, 2006. http://www.iso.org/ iso/iso_catalogue/catalogue_tc/catalogue_detail.htm? csnumber $=38498$.

28. R. Pommier, G. Grimaud, M. Prinçaud, N. Perry, G. Sonnemann, Comparative environmental life cycle assessment of materials in wooden boat ecodesign, Int. J. Life Cycle Assess. 21, 265 (2016). doi:10.1007/s11367-0151009-1.

29. B.P. Weidema, C. Bauer, R. Hischier, C. Mutel, T. Nemecek, J. Reinhard, C.O. Vadenbo, G. Wernet, Overview and methodology. Data quality guideline for the ecoinvent database version 3, Ecoinvent, St. Gallen, Suisse, 2013.

30. International aluminium institute (IAI), Aluminium mass flow Europe 2013, in: Reg. Mass Flow Model. - Part A, World Alum, London, 2014, p. 8. http://www.worldaluminium.org/publications/.

31. European aluminium association (EAA), Environmental profile report for the European aluminium industry 2013, 78 (2013).

32. M. Niero, S.I. Olsen, Circular economy: to be or not to be in a closed product loop? A Life cycle assessment of aluminium cans with inclusion of alloying elements, Resour. Conserv. Recycl. 114, 18 (2015). doi:10.1016/j. resconrec.2016.06.023.

33. B. Lacarrière, K.R. Deutz, N. Jamali-Zghal, O. Le Corre, Emergy assessment of the benefits of closed-loop recycling accounting for material losses, Ecol. Modell. 315, 77 (2015). doi:10.1016/j.ecolmodel.2015.01.015.

34. G. Grimaud, N. Perry, B. Laratte, Life cycle assessment of aluminium recycling process: case of shredder cables, in: Procedia CIRP, Berlin, 2016. doi:10.1016/j.procir.2016.03.097.

35. R. Pommier, G. Grimaud, M. Prinçaud, N. Perry, G. Sonnemann, LCA (Life Cycle Assessment) of EVP engineering veneer product: plywood glued using a vacuum moulding technology from green veneers, J. Clean. Prod. 124, 383 (2016). doi:10.1016/j.jclepro.2016.02.130.

36. G. Grimaud, M. Vuaillat, D. Ravet, B. Laratte, N. Perry, Life cycle assessment of aluminium recycling: case of electric cables, in: Soc. Mater. Int. Conf. (SAM 11) 2, SOVAMAT, Trondheim, Norway, 2017, p. 1.

37. O. Jolliet, M. Saadé, P. Crettaz, S. Shaked, Analyse du cycle de vie: comprendre et réaliser un écobilan, PPUR Presses polytechniques, 2010. http://books.google.com/books?id= g9S55CklsOoC\&pgis=1 (accessed June 26, 2013). 
38. L. Grisel, P. Osset, L'analyse du cycle de vie d'un produit ou d'un service: applications et mises en pratique, Afnor éditions, 2008. http://books.google.com/books?id=SuyQO wAACAAJ\&pgis=1 (accessed June 26, 2013).

39. JRC - Institute for environment and sustainability, The International reference life cycle data system (ILCD) Handbook, in: Int. Ref. Life Cycle Data Syst. Handb. - First Ed., European C, European Commission, Brussels, 2012, p. 72. doi:10.2788/ 85727.

40. IPCC, Climate Change 2007 Synthesis Report, 2007. doi:10.1256/004316502320517344.

41. Office of Acquisition and Project Management, Life cycle cost handbook guidance for life cycle cost estimation and analysis, 89 (2014). http://energy.gov/sites/prod/files/2014/10/f18/ LCC. Handbook Final Version 9- 30-14. pdf.

42. G. Grimaud, N. Perry, B. Laratte, Reducing environmental impacts of aluminium recycling process using life cycle assessment, 12th Bienn. Int. Conf. EcoBalance. 7 (2016). doi:10.1016/j.procir.2016.03.097.
43. P. Peças, U. Götze, E. Henriques, I. Ribeiro, A. Schmidt, C. Symmank, Life Cycle Engineering - Taxonomy and State-ofthe-art, 23rd CIRP Conf. Life Cycle Eng. 48, 73 (2016). doi:10.1016/j.procir.2016.04.085.

44. M.Z. Hauschild, Better - But is it good enough? On the need to consider both eco-efficiency and eco-effectiveness to gauge industrial sustainability, 22nd CIRP Conf. Life Cycle Eng. 29, 1 (2015). doi:10.1016/j.procir.2015. 02.126 .

45. C. Herrmann, S. Blume, D. Kurle, C. Schmidt, S. Thiede, The positive impact factory-transition from eco-efficiency to eco-effectiveness strategies in manufacturing, 22nd CIRP Conf. Life Cycle Eng. 29, 19 (2015). doi:10.1016/j.pro cir.2015.02.066.

46. G. Grimaud, N. Perry, B. Laratte, Évaluation de la performance technique des scénarios de recyclage durant la conception, in: Colloq. Natl. AIP Primeca 2017, CNRS, La Plagne, 2017, pp. 1-7. https://aip-primeca2017.sciencesconf. org $/ 137747 /$ document.

Cite this article as: Guilhem Grimaud, Bertrand Laratte, Nicolas Perry, To transport waste or transport recycling plant: Insights from life-cycle analysis, Matériaux \& Techniques 105, 516 (2017) 